\title{
Impact of Physician Race on Patient Decision-Making and Ratings of Physicians: a Randomized Experiment Using Video Vignettes
}

\author{
Somnath Saha, MD, MPH ${ }^{1,2}$ and Mary Catherine Beach, MD, MPH \\ 'Section of General Internal Medicine, VA Portland Health Care System, Portland, OR, USA; ${ }^{2}$ Division of General Internal Medicine \& Geriatrics, \\ Oregon Health and Science University, Portland, OR, USA; ${ }^{3}$ Department of Medicine, Johns Hopkins University, Baltimore, MD, USA.
}

\begin{abstract}
BACKGROUND: Studies suggest that black patients have better interactions, on average, with physicians of their own race. Whether this reflects greater "cultural competence" in race-concordant relationships, or other effects of race unrelated to physician behavior, is unclear. It is also unclear if physician race influences patient decisionmaking.
\end{abstract}

OBJECTIVE: To determine whether physician race affects patients' ratings of physicians and decision-making, independent of physician behavior.

DESIGN: Randomized study using standardized video vignettes.

PARTICIPANTS: Primary care patients with coronary risk factors or disease.

INTERVENTIONS: Each participant viewed one of 16 vignettes depicting a physician reviewing cardiac catheterization results and recommending coronary artery bypass graft (CABG) surgery. Vignettes varied only in terms of physicians' race, gender, age, and communication style (high vs. low patient-centeredness).

MAIN MEASURES: Participants rated the video physician's communication, interpersonal style, competence, trustworthiness, likability, and overall performance (0-4 Likert scales). They also rated the necessity of CABG (0-5 scale) and whether they would undergo CABG or obtain a second opinion if they were the video patient (0-3 scales). KEY RESULTS: Participants included 107 black and 131 white patients (72\% participation rate). Black participants viewing a black (vs. white) video physician gave higher ratings on all physician attributes (e.g., overall rating 3.22 vs. $2.34, p<0.001$ ) and were more likely to perceive $\mathrm{CABG}$ as necessary ( 4.05 vs. $3.72, p=0.03$ ) and say they would undergo $\mathrm{CABG}$ if they were the video patient ( 2.43 vs. $2.09, p=0.004)$. Patient-centered communication style reduced, but did not eliminate, the impact of race concordance. Physician race was not associated with any outcomes among white patients.

CONCLUSIONS: Black patients viewed the doctor in a scripted vignette more positively, and were more receptive to the same recommendation, communicated in the same way, with a black vs. white physician. Patient-centered

Electronic supplementary material The online version of this article (https://doi.org/10.1007/s11606-020-05646-z) contains supplementary material, which is available to authorized users.

Received October 14, 2019

Revised November 26, 2019

Accepted January 3, 2020

Published online January 21, 2020 communication reduced but did not eliminate the effect of physician race.

KEY WORDS: Black Americans; health care disparities; physician-patient relations; patient decision-making.

J Gen Intern Med 35(4):1084-91 DOI: $10.1007 / \mathrm{s} 11606-020-05646-Z$

(C) Society of General Internal Medicine (This is a U.S. government work and not under copyright protection in the U.S.; foreign copyright protection may apply) 2020

\section{INTRODUCTION}

Prior research has demonstrated that black patients, on average, prefer the care they receive from physicians of their own race. ${ }^{1-4}$ This finding is often presumed to reflect better interpersonal care, including more effective communication and culturally appropriate behavior, from physicians whose shared culture and experience promote greater understanding of patients' preferences and communication styles. ${ }^{2,5}$ This theory has provided one rationale for "cultural competence" training, intended to "bridge the gap" between physicians and patients from different backgrounds. ${ }^{6}$

Another possible explanation for the effects of patientphysician race concordance is that black patients have better experiences with black physicians, independent of physician behavior, because they trust other black people more and view them as less likely to perpetrate discrimination. Numerous studies have shown that people have higher trust and comfort with "ingroup" than with "outgroup" members. ${ }^{7,8}$

If physician race affects patient experience and trust, it may also affect patient decision-making in a way that contributes to disparities in health care. ${ }^{9}$ Prior studies have shown that physicians perceive patients differently and make different clinical decisions based on non-clinical factors such as race, gender, and social class. ${ }^{10-13}$ It is plausible that these perceptions also work in the opposite direction, such that physician characteristics affect patients' decision-making. Understanding the degree to which interpersonal barriers between patients and physicians result from fixed characteristics, such as race, versus modifiable characteristics, such as communication skills and cultural sensitivity, is an important step towards elucidating the causes of disparities in health care and the best avenues to reduce them. 
We conducted a randomized experimental study, using standardized video vignettes, to determine whether physician race affects patients' perceptions and decision-making, independent of physician behavior. We additionally examined whether any effects of physician race were modified by other characteristics, particularly the physician's communication style.

\section{METHODS}

\section{Vignette Development}

Our video vignette portrayed a visit between a physician and a patient with progressive angina who recently underwent coronary angiography revealing 3-vessel coronary artery disease (CAD). ${ }^{14}$ The physician reviews the angiogram results and recommends coronary artery bypass graft (CABG) surgery, citing evidence of improved quality of life and long-term survival. The patient expresses fear about the surgery. The physician provides reassurance, citing statistics about perioperative risks. A discussion ensues about treatment alternatives, including percutaneous intervention and medical management. The physician closes by reiterating the recommendation of $\mathrm{CABG}$.

We chose this scenario for several reasons. First, CABG for chronic angina and 3-vessel CAD is supported by clinical trials and guidelines, making the physician's recommendation evidence-based. ${ }^{15}$ Second, racial disparities in receipt of CABG have been well documented and have persisted for decades. ${ }^{16-18}$ Third, there are substantial risks to either undergoing or foregoing CABG in the setting of 3-vessel CAD. This high-stakes context increases the relevance of patients' trust and confidence in the physician's recommendation. Finally, evidence shows that patients rely heavily on physician recommendations in weighing options for treating CAD. ${ }^{19}$

Because we were also interested in exploring the impact of communication style, we created two versions of the vignette, with the physician using a low vs. high patient-centered communication (PCC) style. We first chose two core principles of PCC: a biopsychosocial orientation and a partnered approach in doctor-patient interactions. ${ }^{20}$ We then chose verbal and nonverbal communication behaviors commonly mentioned as ways of promoting these ideals (Table 1). ${ }^{21,22}$ We varied these behaviors but kept the vignettes the same in other respects, including clinical information, numeric estimates of risk and benefit, and strength of recommendation. In a previous study, our high PCC vignettes were associated with higher ratings of

Table 1 Characteristics of Low and High Patient-Centeredness

\begin{tabular}{lll}
\hline \hline Patient-Centeredness & Low & High \\
\hline Patient participation & Low & High \\
Affect & Neutral, "businesslike" & Positive \\
Language & Biomedical/complex & Lay \\
Information giving & Low & High \\
Empathy & Low & High \\
Time & Shorter & Longer \\
Eye contact & Low & High \\
\hline
\end{tabular}

the video physician on multiple dimensions including communication, validating that the 2 versions captured intended differences in communication style. ${ }^{14}$

We filmed 32 videos: 8 physician actors - each representing a unique combination of black vs. white, male vs. female, and young vs. middle-aged (Fig.1) - performing 2 vignette versions (low and high PCC), each with 2 patient voices (male and female). To facilitate study participants assuming the role of the patient, vignettes were filmed from a point-of-view angle: the patient was heard but not seen, and the physician faced the camera when speaking. Each video introduces the patient as a 55-year-old woman or man with hypertension and progressive chest pain, who had a positive exercise treadmill test leading to an angiogram. The introduction explains what an angiogram is and that this is the patient's 2nd visit to this physician, with the purpose of discussing angiogram results.

\section{Setting, Participants, and Study Procedures}

We recruited study participants at a hospital-based primary care clinic in the Pacific Northwest. We approached consecutive patients 40 or older whose records indicated a diagnosis of $\mathrm{CAD}$ or $\mathrm{CAD}$ risk factors (smoking, hypertension, diabetes, or hyperlipidemia), to increase the relevance of a vignette about CAD treatment options. Participants were told the study purpose was to examine patients' decision-making about heart disease, and that when watching the vignette, they should place themselves in the role of the video patient. Acutely ill patients and those with cognitive or severe visual impairment were ineligible. The study was approved by the Legacy Health System Institutional Review Board.

After giving informed consent, participants completed a brief questionnaire evaluating demographic characteristics, cardiac history, familiarity with and knowledge about different CAD treatment options, experience of racial discrimination when receiving health care, ${ }^{23}$ and trust in health care. ${ }^{24}$

\section{Randomization}

Each of our 32 videos was given an alphanumeric code. Once enrolled, research assistants assigned participants to a vignette based on computer-generated randomized lists generated by the principal investigator (SS). Male and female participants were assigned to vignettes with a male or female patient voice, respectively. Research assistants were unaware of the alphanumeric codes linked to each video. The principal investigator was not involved in enrolling participants.

\section{Outcome Measures}

After viewing the assigned video, participants completed a questionnaire assessing their impressions of the video physician and the recommendation of CABG (Appendix). Participants rated the physician's communication (5 items, Cronbach's alpha 0.95), ${ }^{25}$ interpersonal style ( 5 items, alpha $0.92),{ }^{26}$ and competence (4 items, alpha 0.84 ). They also reported 

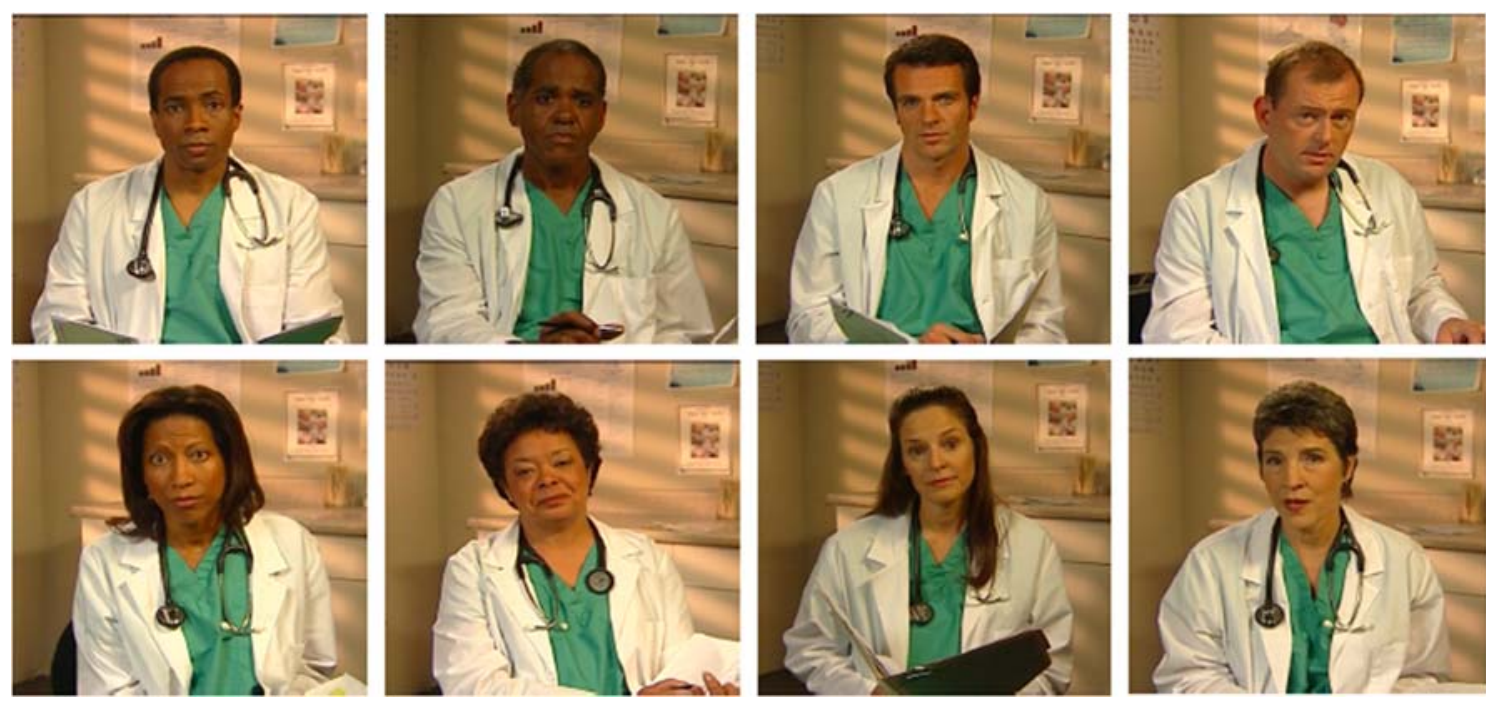

Fig. 1 Actors portraying physicians.

on their trust in the video physician (10 items, alpha 0.94$),{ }^{27}$ how much they liked and felt comfortable with the physician (3 items, alpha 0.94$)$, and their perceptions of the physician overall (1 item). Participants reported their perception of the necessity of CABG for the patient in the video (0-5 scale from absolutely unnecessary to absolutely necessary). They also rated their likelihood of undergoing $\mathrm{CABG}$ and of obtaining a second opinion, if they were the patient in the video, and their sense of whether the benefits of $\mathrm{CABG}$ outweighed the risks (all using 0 $0-3$ scale from definitely not to definitely).

\section{Data Analysis}

We used $t$ tests and chi-square tests to compare participant characteristics by race and condition assignment (video physician race). We stratified all analyses of the effects of physician race, by participant race. To account for any within-videophysician correlations (i.e., individual actor effects), we tested statistical significance using GEE-based linear regression analyses with video physician actor as the cluster variable.

We conducted interaction analyses to test whether any observed effects of physician race were modified by communication style (high vs. low PCC). We similarly tested for interactions between physician race and physician gender, patient gender, patient-physician gender concordance, patient age, experience of discrimination, and trust in health care, to see if the impact of physician race varied by these characteristics. Where significant interactions were observed, we repeated our main analyses, stratified by levels of the modifying variable. Analyses were conducted using Stata/SE 14 (College Station, TX, USA).

\section{RESULTS}

\section{Participant Characteristics}

We approached 373 patients; 27 were ineligible and 98 declined (Fig. 2). Participants were younger than those who declined (57.8 vs. 62.3 ) and more likely to be black (45\% vs. $41 \%$ ) and female (59\% vs. $52 \%$ ). Among the 248 participants completing the study ( $72 \%$ participation rate), 10 selfidentified as other than black or white. Among the remaining 238, the 107 black participants were less likely than the 131 white participants to have completed high school (78\% vs. $91 \%, p=0.007)$, to report having CAD $(16 \%$ vs. $27 \%, p=$ $0.03)$, to have undergone CABG ( $0 \%$ vs. $7 \%, p=0.006)$, to have familiarity with CABG ( $39 \%$ vs. $56 \%, p=0.008)$, and to feel knowledgeable about CABG (33\% vs. $50 \%, p=0.006)$. Prior to viewing a video vignette, black participants were more likely than whites to perceive the mortality risk of CABG as above $10 \%$ ( $48 \%$ vs. $32 \%, p=0.02$ ). They also more frequently reported having experienced racial discrimination in healthcare settings $(50 \%$ vs. $12 \%, p<0.001)$ and had lower levels of trust in the healthcare system (2.93 vs. 3.19 on $1-5$ scale, $p=0.001$ ). Participant characteristics were balanced across randomization groups (Table 2).

\section{Ratings of Video Physicians}

Black participants gave higher ratings on all physician attributes - communication, interpersonal style, competence, trustworthiness, and likability - and a superior overall rating, when the video physician was black rather than white (Table 3). For white participants, there were no significant differences by physician race.

\section{Decision-Making Outcomes}

Black participants viewing a vignette with a black physician rated the necessity of CABG significantly higher and indicated they would be more likely to undergo CABG if they were the patient in the video, compared with black participants viewing a white physician (Table 4). Black participants who viewed a race-concordant physician also expressed a somewhat lower desire for a second opinion, though this was not statistically significant. Race concordance was not associated with CABG 


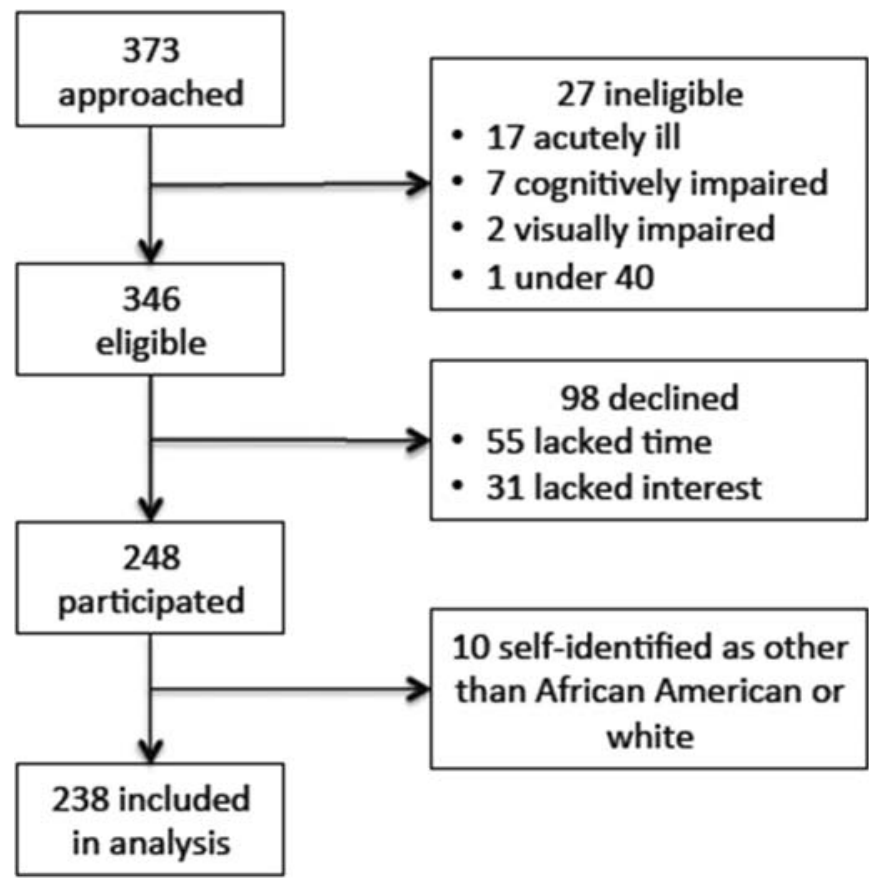

Fig. 2 Study recruitment.

risk/benefit perceptions. For white participants, there were no differences in decision-making outcomes by physician race.

\section{Interactions of Physician Race with Other Variables}

The effect of physician race on ratings and decision-making outcomes among black patients was generally less pronounced with higher PCC (Table 5). For instance, the difference in overall ratings of the black vs. white physicians was significantly greater for low vs. high PCC vignettes (1.56 vs. 0.57 , $p=0.03$ for physician race by PCC interaction). Similar patterns were seen with the outcomes of interpersonal style, trustworthiness, likability, and perceived necessity of CABG. Even with the high PCC vignettes, however, the effect of race on ratings of the physician and expressed likelihood of undergoing $\mathrm{CABG}$ remained significant.

We found no interactions between video physician race and patient gender, physician gender, or patient-physician gender concordance. We did find interactions between video physician race and patient age, experience of discrimination, and trust in the healthcare system, for specific outcomes. Patient age modified the effect of race concordance on ratings of physician competence; black participants 60 and over perceived the black physicians as more competent (3.56 vs. $2.58, p<0.001)$, but those under $60 \mathrm{did}$ not $(3.20$ vs. 2.91 , $p=0.17$ ). Among black participants reporting prior discrimination, race concordance was associated with a more favorable risk/benefit tradeoff perception (2.61 vs. $2.10, p=0.003$ ); a trend toward the reverse finding (better outcome with race discordance) was seen among those not reporting discrimination ( 2.37 vs. $2.65, p=0.051$ ). Among black participants with less trust in health care $($ score $<3.5)$, race concordance was associated with higher perceived need for CABG (4.03 vs. $3.59, p=0.015)$; this association was not observed among those with a higher trust score ( 4.13 vs. $4.33, p=0.09)$. Finally, race concordance was associated with a more favorable perceived risk/benefit tradeoff ( 2.60 vs. $1.69, p=0.001)$ among black participants with a trust score less than 2.5 , but not among those with higher trust ( 2.44 vs. $2.55, p=0.40$ ).

Table 2 Baseline Participant Characteristics, by Video Physician Race

\begin{tabular}{lll}
\hline \hline Participant characteristics & $\begin{array}{l}\text { Video physician race } \\
(\boldsymbol{n})\end{array}$ \\
\cline { 2 - 3 } & $\begin{array}{l}\text { Black } \\
\mathbf{( 1 1 6 )}\end{array}$ & $\begin{array}{l}\text { White } \\
\mathbf{( 1 2 2})\end{array}$ \\
\hline Race & & \\
Black, $n(\%)$ & $54(47 \%)$ & $53(43 \%)$ \\
White, $n(\%)$ & $62(54 \%)$ & $69(57 \%)$ \\
Age, mean (SD) & 56.7 & 58.9 \\
Female, $n(\%)$ & $(10.9)$ & $(10.9)$ \\
Completed high school, $n(\%)$ & $69(59 \%)$ & $71(58 \%)$ \\
& $99(85 \%)$ & 103 \\
Fair/poor health status, $n(\%)$ & & $(85 \%)$ \\
Current cigarette smoker, $n(\%)$ & $57(49 \%)$ & $53(44 \%)$ \\
Known CAD, $n(\%)$ & $40(35 \%)$ & $36(30 \%)$ \\
History of CABG, $n(\%)$ & $30(26 \%)$ & $23(19 \%)$ \\
Very/somewhat familiar with CABG, $n(\%)$ & $4(3 \%)$ & $5(4 \%)$ \\
Very/somewhat knowledgeable about & $51(49 \%)$ & $59(48 \%)$ \\
CABG, $n(\%)$ & $50(41 \%)$ \\
Perceived mortality risk of CABG $>10 \%, n$ & $47(42 \%)$ & $43(36 \%)$ \\
$(\%)$ & $33(29 \%)$ & $37(31 \%)$ \\
Perceived racial discrimination when & & \\
receiving health care, $n(\%)$ & $62(53 \%)$ & $59(48 \%)$ \\
Female video physician, $n(\%)$ & $60(52 \%)$ & $70(57 \%)$ \\
Video physician with high PCC style, $n(\%)$ & & \\
\hline
\end{tabular}

$C A D$, coronary artery disease; $C A B G$, coronary artery bypass graft surgery; $P C C$, patient-centered communication 
Table 3 Ratings of Video Physician, by Participant and Video Physician Race

\begin{tabular}{|c|c|c|c|c|c|c|}
\hline \multirow{2}{*}{$\begin{array}{l}\text { Study participant race }(n): \\
\text { Video physician race }(n):\end{array}$} & \multicolumn{3}{|l|}{ Black (107) } & \multicolumn{3}{|l|}{ White (131) } \\
\hline & Black (54) & White (53) & $p$ & Black (62) & White (69) & $p$ \\
\hline Communication, mean (SD) & $3.32(0.89)$ & $2.68(1.12)$ & $<0.001$ & $2.72(1.04)$ & $2.52(1.19)$ & 0.30 \\
\hline Interpersonal style, mean (SD) & $3.51(0.63)$ & $3.02(0.83)$ & 0.005 & $3.02(0.90)$ & $2.96(1.01)$ & 0.69 \\
\hline Competence, mean (SD) & $3.34(0.85)$ & $2.76(0.91)$ & $<0.001$ & $2.90(0.85)$ & $2.89(0.90)$ & 0.46 \\
\hline Trustworthiness, mean (SD) & $3.12(0.80)$ & $2.37(0.95)$ & $<0.001$ & $2.47(0.90)$ & $2.58(0.86)$ & 0.45 \\
\hline Likability, mean (SD) & $3.39(0.79)$ & $2.69(1.09)$ & $<0.001$ & $2.54(1.07)$ & $2.68(1.14)$ & 0.49 \\
\hline Overall rating, mean (SD) & $3.22(0.95)$ & $2.34(1.25)$ & $<0.001$ & $2.50(1.14)$ & $2.42(1.18)$ & 0.74 \\
\hline
\end{tabular}

Possible range for all variables was 0-4. p values are based on linear generalized estimating equation (GEE) models to account for clustering by video physician (actor)

\section{DISCUSSION}

In this randomized experiment, we found that black patients viewed the doctor in a scripted video vignette more positively, and were more receptive to the same recommendation, communicated in the same way, with a black rather than white physician. The effect of physician race was reduced, but not eliminated, when the physician used more PCC behaviors. For white patients, physician race did not affect patient perceptions or decision-making.

Numerous studies have demonstrated that patient-physician race concordance is associated with higher ratings of physicians and better perceived communication, particularly among black patients. ${ }^{2,4}$ It is commonly argued that these findings reflect clinical interactions with greater cultural concordance, less racial bias, or more similar communication styles between physicians and patients from the same background. ${ }^{2,5,6}$ Our findings suggest that at least part of the effect of race concordance may be unrelated to physician behavior, driven instead by experiences and perceptions shaped by influences outside the clinical encounter.

Prior studies provide supportive evidence for this hypothesis. In a study using virtual reality technology, Persky et al. found that African-Americans had more accurate perceptions of lung cancer risk after receiving information from an African-American, compared with a white, physician avatar. ${ }^{28}$ Whittle et al. found that black patients more often expressed willingness to undergo a cardiac procedure when interviewed by a black vs. white research assistant using the same survey script. $^{29}$

These findings should not be surprising. Black Americans have endured systematic oppression that provides ample reason to trust members of their own community over others. The racism that gave rise to segregation, economic deprivation, mass incarceration, redlining, police brutality, and the Tuskegee syphilis study still pervades our society and its institutions, including our healthcare system. ${ }^{30-32}$ In this context, it is understandable that black patients might be more comfortable with black physicians, and more likely to trust their recommendations. Notably, the effect of race concordance on perceptions of the physician's recommendation in our study was more pronounced among participants reporting prior discrimination and lower trust in health care. It should also be unsurprising that physician race did not influence white patients' perceptions and decision-making, as they have not been on the receiving end of the racial oppression that likely underlies the impact of physician race for black patients.

Studies examining whether the effects of race concordance go beyond patient experience and perceptions have generally found that concordance does not influence other aspects of healthcare quality, including receipt of basic services. ${ }^{33,34}$ This may reflect the fact that meeting those quality metrics is driven primarily by physician decision-making, ordering, and referrals. Our findings, and those of other studies, suggest that there may be downstream effects of race concordance that are more dependent on patient decision-making, such as acceptance of high-stakes recommendations, adherence to treatment plans, and engagement in care. ${ }^{35,36}$

We strongly caution against the interpretation of our results as suggesting that minority patients should be preferentially assigned to physicians of their own race. The impact of physician race on black patients' trust and comfort, while present on average, is not universal, and presumptions should never be made about individual patients' preferences. We do believe, however, that in relationships as personal as that between patient and physician, where private and sensitive information is shared and high-stakes decisions are made, patients should

Table 4 Decision-making Outcomes, by Participant and Video Physician Race

\begin{tabular}{|c|c|c|c|c|c|c|}
\hline \multirow{2}{*}{$\begin{array}{l}\text { Study participant race }(n): \\
\text { Video physician race }(n):\end{array}$} & \multicolumn{3}{|l|}{ Black (107) } & \multicolumn{3}{|l|}{ White (131) } \\
\hline & Black (54) & White (53) & $p$ & Black (62) & White (69) & $p$ \\
\hline Perceived necessity of CABG (range $0-5$ ), mean (SD) & $4.05(0.86)$ & $3.72(1.31)$ & 0.03 & $3.98(0.79)$ & $3.91(0.87)$ & 0.63 \\
\hline Likelihood of undergoing CABG (range $0-3$ ), mean (SD) & $2.43(0.77)$ & $2.09(0.95)$ & 0.004 & $2.29(0.78)$ & $2.30(0.77)$ & 0.93 \\
\hline Likelihood of getting 2 nd opinion (range $0-3$ ), mean (SD) & $2.43(0.89)$ & $2.68(0.73)$ & 0.08 & $2.11(1.01)$ & $2.14(1.03)$ & 0.89 \\
\hline Perceived benefits of CABG outweigh risk (range $0-3$ ), mean (SD) & $2.47(0.70)$ & $2.34(0.85)$ & 0.26 & $2.60(0.66)$ & $2.58(0.69)$ & 0.87 \\
\hline
\end{tabular}

$C A B G$, coronary artery bypass graft surgery. $p$ values are based on linear generalized estimating equation (GEE) models to account for clustering by video physician (actor) 
Table 5 Ratings and Decision-Making Among Black Study Participants, by Level of Patient-Centered Communication Style and Video Physician Race

\begin{tabular}{|c|c|c|c|c|c|c|c|c|}
\hline \multirow{2}{*}{$\frac{\text { Video physician patient-centeredness }(n):}{\text { Video physician race }(n):}$} & \multicolumn{4}{|l|}{ Low (47) } & \multicolumn{4}{|l|}{ High (60) } \\
\hline & AA (27) & $\begin{array}{l}\text { White } \\
\text { (20) }\end{array}$ & $\begin{array}{l}\text { AA-white } \\
\text { difference }\end{array}$ & $p$ & AA (27) & $\begin{array}{l}\text { White } \\
\text { (33) }\end{array}$ & $\begin{array}{l}\text { AA-white } \\
\text { difference }\end{array}$ & $p$ \\
\hline \multicolumn{9}{|l|}{ Rating of video physician } \\
\hline Communication, mean (SD) & $2.92(1.05)$ & $1.89(1.18)$ & 1.03 & $<0.001$ & $3.72(.42)$ & $3.16(.76)$ & 0.56 & $<0.001$ \\
\hline Interpersonal style, mean (SD)* & $3.27(.75)$ & $2.37(.92)$ & 0.90 & $<0.001$ & $3.74(.35)$ & $3.41(.44)$ & 0.33 & $<0.001$ \\
\hline Competence, mean (SD) & $3.06(1.04)$ & $2.26(1.03)$ & 0.80 & 0.003 & $3.63(.48)$ & $3.06(.69)$ & 0.57 & $<0.001$ \\
\hline Trustworthiness, mean (SD)* & $2.91(1.01)$ & $1.65(.98)$ & 1.26 & $<0.001$ & $3.33(.46)$ & $2.81(.62)$ & 0.52 & $<0.001$ \\
\hline Likability, mean (SD)* & $3.23(.96)$ & $1.88(1.22)$ & 1.35 & $<0.001$ & $3.54(.55)$ & $3.17(.63)$ & 0.37 & 0.009 \\
\hline Overall rating, mean $(\mathrm{SD})^{*}$ & $2.96(1.16)$ & $1.40(1.14)$ & 1.56 & $<0.001$ & $3.48(.58)$ & $2.91(.95)$ & 0.57 & 0.005 \\
\hline \multicolumn{9}{|l|}{ Decision-making } \\
\hline $\begin{array}{l}\text { Perceived necessity of CABG, } \\
\text { mean (SD)* }\end{array}$ & $3.73(.87)$ & $2.80(1.58)$ & 0.93 & 0.007 & $4.37(.74)$ & $4.27(.67)$ & 0.10 & 0.50 \\
\hline $\begin{array}{l}\text { Likelihood of undergoing CABG, } \\
\text { mean (SD) }\end{array}$ & $2.12(.91)$ & $1.45(1.05)$ & 0.67 & 0.005 & $2.74(.45)$ & $2.48(.62)$ & 0.26 & 0.04 \\
\hline $\begin{array}{l}\text { Likelihood of getting 2nd opinion, } \\
\text { mean (SD) }\end{array}$ & $2.62(.75)$ & $2.90(.45)$ & -0.28 & 0.11 & $2.26(.98)$ & $2.55(.83)$ & -0.29 & 0.15 \\
\hline $\begin{array}{l}\text { Perceived benefits of CABG outweigh } \\
\text { risk, mean (SD) }\end{array}$ & $2.27(.72)$ & $1.95(1.00)$ & 0.32 & 0.20 & $2.67(.62)$ & $2.58(.66)$ & 0.09 & 0.58 \\
\hline
\end{tabular}

$*_{p}<0.05$ for test of interaction between video physician race and level of patient-centered communication style

have latitude to choose a physician with whom they feel comfortable. It has become generally accepted that women be allowed to choose a gender-concordant physician if they prefer. To the extent that race creates similar issues around patient comfort and safety, minority patients should be able to choose a race-concordant physician if they prefer.

Prior studies have shown that minority patients do disproportionately seek out physicians from their own background. ${ }^{3,37}$ Many patients, however, are unable to see a raceconcordant physician, even if preferred, because of the undersupply of minority physicians. Black Americans currently make up $13 \%$ of the U.S. population ${ }^{38}$ but only $6 \%$ of physicians. ${ }^{39}$ Latinos likewise comprise $18 \%$ of the population but $5 \%$ of physicians. ${ }^{38,39}$ Given widespread racial disparities in health care, and the findings from our study suggesting that race discordance may affect trust and decision-making in ways that contribute to these disparities, remedying the underrepresentation of minority physicians should be a national priority.

Diversifying the physician workforce will take time. In the meantime, our findings provide evidence that the "social distance" between some patients and physicians in racediscordant relationships can be at least partially bridged through effective communication. ${ }^{40,41}$ While PCC behaviors are likely to enhance all relationships, they may be particularly important in the setting of race discordance or other differences that create interpersonal distance between patients and physicians. Many physicians do not believe they contribute to racial disparities because they treat all patients equally. ${ }^{42}$ But equal treatment is likely to maintain, rather than ameliorate, existing disparities. Reducing disparities may require that physicians invest more heavily in rapport and relationship building in situations, like race discordance, where there may be greater social distance to bridge than in the average clinical interaction.

\section{Limitations}

We recruited patients from a single setting with relatively few black physicians. Lack of significant prior exposure to black physicians might have influenced our results for both black and white participants. Extending this study to different regions of the country would help determine if our results are broadly generalizable. We measured patients' reactions to a simulated scenario about a specific procedure. We used CABG as a model for reasons described above. While we believe our findings are likely to be generalizable to other high-stakes clinical decisions, this could be tested in future studies. Finally, we evaluated hypothetical, rather than real, decision-making. Prior studies, however, have found the perceptions of analog patients to be reliable and valid predictors of real patients' perceptions. ${ }^{43,44}$ Moreover, simulated encounters confer the benefit of isolating the effects of specific variables, and in this study, we were able to study the impact of race, independent of other factors. We were also able to avoid the problem of skewed ratings when patients evaluate their own physicians. ${ }^{44}$

\section{CONCLUSION}

We found that black patients viewed black physicians more positively than white physicians, even when physicians gave the same information in the same manner. Race concordance also affected patients' decision-making in the context of an evidence-based, high-stakes recommendation. These differences were reduced, but not eliminated, when physicians used PCC behaviors. These findings suggest that physician race may affect outcomes of patient-physician interactions in ways that are unrelated to physician behavior, and that communication or cultural competence training is likely to be only a 
partial solution to disparities stemming from racial barriers in patient-physician relationships. Our findings add further evidence that increasing the racial diversity of the physician workforce may help reduce disparities in health care.

Acknowledgments: This research was supported by the Robert Wood Johnson Foundation. Dr. Saha was additionally supported by the United States Department of Veterans Affairs.

Corresponding Author: Somnath Saha, MD, MPH; Section of General Internal Medicine VA Portland Health Care System, 3710 SW U.S. Veterans Hospital Rd. (P3HSRD), Portland, OR, USA (e-mail: sahas@ohsu.edu).

\section{Compliance with Ethical Standards:}

Conflict of Interest: The authors declare that they do not have a conflict of interest.

Disclaimer: The sponsors played no role in the study design; the collection, analysis, and interpretation of data; the writing of the report; or the decision to submit the paper for publication. The views expressed in this article are those of the authors and not necessarily those of the United States Department of Veterans Affairs or the Robert Wood Johnson Foundation.

\section{REFERENCES}

1. Saha S, Komaromy M, Koepsell TD, Bindman AB. Patient-physician racial concordance and the perceived quality and use of health care. Arch Intern Med 1999;159:997-1004.

2. Saha S, Shipman SA. The rationale for diversity in the health professions: a review of the evidence. Hyattsville, Md.: U.S. Department of Health and Human Services, Health Resources and Services Administration, Bureau of Health Professions; 2006.

3. Saha S, Taggart SH, Komaromy M, Bindman AB. Do patients choose physicians of their own race? Health Aff (Millwood) 2000;19:76-83.

4. Shen MJ, Peterson EB, Costas-Muniz R, et al. The effects of race and racial concordance on patient-physician communication: a systematic review of the literature. J Racial Ethn Health Disparities 2018;5:117-40.

5. Cooper LA, Powe NR. Disparities in patient experiences, health care processes, and outcomes: the role of patient-provider racial, ethnic, and language concordance July 2004.

6. Eiser AR, Ellis G. Viewpoint: cultural competence and the African American experience with health care: the case for specific content in cross-cultural education. Acad Med 2007;82:176-83.

7. Brewer MB. The social psychology of intergroup relations: social categorization, ingroup bias, and outgroup prejudice. In: Kruglanski AW, Higgins ET, eds. Social Psychology: Handbook of Basic Principles. New York: The Guilford Press; 2007:695-715.

8. Hewstone M, Rubin M, Willis H. Intergroup bias. Ann Rev Psychol 2002;53:575-604.

9. Smedley BD, Stith AY, Nelson AR, Institute of Medicine (U.S.). Committee on Understanding and Eliminating Racial and Ethnic Disparities in Health Care. Unequal Treatment: Confronting Racial and Ethnic Disparities in Health Care. Washington, D.C.: National Academies Press; 2003.

10. Berger JT. The influence of physicians' demographic characteristics and their patients' demographic characteristics on physician practice: implications for education and research. Acad Med 2008;83:100-5.

11. Burgess DJ, Crowley-Matoka M, Phelan S, et al. Patient race and physicians' decisions to prescribe opioids for chronic low back pain. Soc Sci Med 2008;67:1852-60.

12. Hajjaj FM, Salek MS, Basra MK, Finlay AY. Non-clinical influences on clinical decision-making: a major challenge to evidence-based practice. $J$ R Soc Med 2010;103:178-87.

13. Schulman KA, Berlin JA, Harless W, et al. The effect of race and sex on physicians' recommendations for cardiac catheterization. N Engl J Med 1999;340:618-26.
14. Saha S, Beach MC. The impact of patient-centered communication on patients' decision making and evaluations of physicians: a randomized study using video vignettes. Patient Educ Couns 2011;84:386-92.

15. Neumann FJ, Sousa-Uva M, Ahlsson A, et al. 2018 ESC/EACTS Guidelines on myocardial revascularization. Eur Heart J 2019;40:87165.

16. Angraal S, Khera $\mathbf{R}$, Wang $\mathbf{Y}$, et al. Sex and race differences in the utilization and outcomes of coronary artery bypass grafting among Medicare beneficiaries, 1999-2014. J Am Heart Assoc 2018;7.

17. Gillum RF, Gillum BS, Francis CK. Coronary revascularization and cardiac catheterization in the United States: trends in racial differences. J Am Coll Cardiol 1997;29:1557-62.

18. Jha AK, Fisher ES, Li Z, Orav EJ, Epstein AM. Racial trends in the use of major procedures among the elderly. N Engl J Med 2005;353:683-91.

19. BeLue R, Butler $\mathbf{J}$, Kuder J. Implications of patient and physician decision making: an illustration in treatment options for coronary artery disease. J Ambul Care Manage 2004;27:305-13.

20. Lewin SA, Skea ZC, Entwistle V, Zwarenstein M, Dick J. Interventions for providers to promote a patient-centred approach in clinical consultations. Cochrane Database Syst Rev 2001:CD003267.

21. Ong LM, de Haes JC, Hoos AM, Lammes FB. Doctor-patient communication: a review of the literature. Soc Sci Med 1995;40:903-18.

22. Roter D. Patient-centered communication. BMJ 2004;328:E303-4.

23. Johnson RL, Saha S, Arbelaez JJ, Beach MC, Cooper LA. Racial and ethnic differences in patient perceptions of bias and cultural competence in health care. J Gen Intern Med 2004;19:101-10.

24. Rose A, Peters N, Shea JA, Armstrong K. Development and testing of the health care system distrust scale. J Gen Intern Med 2004;19:57-63.

25. Saha S, Arbelaez JJ, Cooper LA. Patient-physician relationships and racial disparities in the quality of health care. Am J Public Health 2003;93:1713-9.

26. Stewart AL, Napoles-Springer AM, Gregorich SE, Santoyo-Olsson J. Interpersonal processes of care survey: patient-reported measures for diverse groups. Health Serv Res 2007;42:1235-56.

27. Anderson LA, Dedrick RF. Development of the Trust in Physician scale: a measure to assess interpersonal trust in patient-physician relationships. Psychol Rep 1990;67:1091-100.

28. Persky S, Kaphingst KA, Allen VC, Jr., Senay I. Effects of patientprovider race concordance and smoking status on lung cancer risk perception accuracy among African-Americans. Ann Behav Med 2013;45:308-17.

29. Whittle J, Conigliaro J, Good CB, Joswiak M. Do patient preferences contribute to racial differences in cardiovascular procedure use? J Gen Intern Med 1997;12:267-73.

30. Cooper LA, Roter DL, Carson KA, et al. The associations of clinicians' implicit attitudes about race with medical visit communication and patient ratings of interpersonal care. Am J Public Health 2012;102:97987.

31. Feagin J, Bennefield Z. Systemic racism and U.S. health care. Soc Sci Med 2014;103:7-14

32. Shavers VL, Fagan P, Jones D, et al. The state of research on racial/ ethnic discrimination in the receipt of health care. Am J Public Health 2012;102:953-66.

33. Traylor AH, Subramanian U, Uratsu CS, Mangione CM, Selby JV, Schmittdiel JA. Patient race/ethnicity and patient-physician race/ ethnicity concordance in the management of cardiovascular disease risk factors for patients with diabetes. Diabetes Care 2010;33:520-5.

34. Meghani SH, Brooks JM, Gipson-Jones T, Waite R, Whitfield-Harris L, Deatrick JA. Patient-provider race-concordance: does it matter in improving minority patients' health outcomes? Ethn Health 2009; 14:107-30

35. Ma A, Sanchez A, Ma M. The impact of patient-provider race/ethnicity concordance on provider visits: updated evidence from the Medical Expenditure Panel Survey. J Racial Ethn Health Disparities 2019;6:1011-20. .

36. Traylor AH, Schmittdiel JA, Uratsu CS, Mangione CM, Subramanian U. Adherence to cardiovascular disease medications: does patientprovider race/ethnicity and language concordance matter? J Gen Intern Med 2010;25:1172-7.

37. Traylor AH, Schmittdiel JA, Uratsu CS, Mangione CM, Subramanian U. The predictors of patient-physician race and ethnic concordance: a medical facility fixed-effects approach. Health Serv Res 2010;45:792-805.

38. Quick facts, United States. U.S. Census Bureau. (Accessed October 9, 2019, at https://www.census.gov/quickfacts/fact/table/US/ PST045218.) 
39. Distribution of allopathic medical school graduates by race/ethnicity Kaiser Family Foundation. (Accessed October 9, 2019, at https://www. kff.org/other/state-indicator/allopathic-distribution-by-race-ethnicity/.)

40. Street RL, Jr., O'Malley KJ, Cooper LA, Haidet P. Understanding concordance in patient-physician relationships: personal and ethnic dimensions of shared identity. Ann Fam Med 2008;6:198-205.

41. Thornton RL, Powe NR, Roter D, Cooper LA. Patient-physician social concordance, medical visit communication and patients' perceptions of health care quality. Patient Educ Couns 2011;85:e201-8.

42. Eliacin J, Cunningham B, Partin MR, et al. Veterans Affairs providers beliefs about the contributors to and responsibility for reducing racial and cthnic health care disparities. Health Equity 2019;3:436-48.
43. Blanch-Hartigan D, Hall JA, Krupat E, Irish JT. Can naive viewers put themselves in the patients' shoes?: reliability and validity of the analogue patient methodology. Med Care 2013;51:e16-21.

44. van Vliet $\mathbf{L M}$, van der Wall E, Albada A. Spreeuwenberg PM, Verheul $\mathbf{W}$, Bensing JM. The validity of using analogue patients in practitionerpatient communication research: systematic review and meta-analysis. J Gen Intern Med 2012;27:1528-43.

Publisher's Note Springer Nature remains neutral with regard to jurisdictional claims in published maps and institutional affiliations. 